\title{
TRIPLE IMMUNOSUPPRESSION REDUCES MONONUCLEAR CELL INFILTRATION AND PROLONGS GRAFT LIFE IN PIG-TO-NEWBORN BABOON CARDIAC XENOTRANSPLANTATION
}

Oktavijan P. Minanov, MD ${ }^{\mathrm{a}, \mathrm{b}}$ John H. Artrip, MD ${ }^{\mathrm{a}, \mathrm{b}}$

Matthias Szabolcs, MD $^{\mathrm{c}}$

Pawel A. Kwiatkowski, MD ${ }^{\mathrm{a}, \mathrm{b}}$

Uri Galili, $\mathrm{PhD}^{\mathrm{d}}$

Silviu Itescu, MD ${ }^{\mathrm{a}, \mathrm{b}}$

Robert E. Michler, MD ${ }^{\mathrm{a}, \mathrm{b}, \mathrm{e}}$
Objective: Pig hearts transplanted into unmedicated newborn baboons do not undergo hyperacute rejection by preformed xenoantibody and complement. These grafts are rejected at days 3 to 4 in association with the infiltration of macrophages and natural killer cells. We investigated whether an immunosuppressive regimen used widely in cardiac allotransplantation could reduce this cellular response and prolong xenograft life. Methods: Ten newborn baboons underwent heterotopic pig cardiac xenotransplantation. Five baboons were immunosuppressed with mycophenolate mofetil (100 mg/kg), methylprednisolone acetate $(0.8 \mathrm{mg} / \mathrm{kg})$, and cyclosporine A (INN: ciclosporin; $10 \mathrm{mg} / \mathrm{kg}$ ). Xenograft rejection was studied by light microscopy and immunofluorescence. The induced humoral response to porcine xenoantigens was documented by enzyme-linked immunosorbent assay using synthetic $\alpha$-1,3-galactosyl epitopes coupled to bovine serum albumin. Results: Graft life was extended from a mean of $3.6 \pm 0.5$ days $(n=5)$ to a mean of $6.2 \pm 1.1$ days $(n=5, p=0.01)$. In comparison with controls, explanted grafts from medicated baboons demonstrated reduced infiltration with natural killer cells and macrophages, but increased evidence of complement-mediated rejection substantiated by increased deposition of immunoglobulin $\mathrm{M}$, complement, and fibrin. In all baboons receiving transplants, levels of both immunoglobulin $M$ and immunoglobulin $\mathbf{G}$ anti-galactose were significantly increased after transplantation, with immunoglobulin $\mathbf{G}$ levels remaining persistently elevated. Conclusions: These results indicate that cyclosporine-based triple immunosuppression marginally prolonged xenograft survival and appears to have reduced the natural killer cell and macrophage infiltrates. The immunosuppressive protocol, however, was not adequate to prevent the induced immunoglobulin $M$ humoral response and prevent complement-mediated graft injury. (J Thorac Cardiovasc Surg 1998;115:998-1006)
C ardiac transplantation has progressed to the point at which it currently represents the best therapeutic option available to patients with endstage heart disease. The supply of human donor hearts, however, remains inadequate to meet the ever-increasing demand. The severe shortage of donor hearts is especially acute in the pediatric

From the Cardiac Transplantation Research Laboratory a and the Departments of Surgery ${ }^{\mathrm{b}}$ and Pathology ${ }^{\mathrm{c}}$ College of Physicians and Surgeons, Columbia University, New York, N.Y., the Department of Microbiology and Immunology, ${ }^{\mathrm{d}}$ Medical College of Pennsylvania, Hahnemann University, Philadelphia, Pa., and Ohio State University Medical Center, ${ }^{\mathrm{e}}$ Columbus, Ohio.

Supported in part by a gift from Roche Pharmaceuticals.

Read in part at the Seventeenth Annual Meeting of the International Society of Heart and Lung Transplantation, London, United Kingdom, April 3-6, 1997. population. This situation has been further exacerbated by the inability to use mechanical assist devices as "a bridge," sustaining pediatric patients in need of a heart transplant until an appropriate donor is located. This situation has prompted the investigation of xenografts as an alternative source of organs for human beings. The similar physiology

Received for publication April 22, 1997; revisions requested August 11, 1997; revisions received Nov. 25, 1997; accepted for publication Dec. 5, 1997.

Address for reprints: Robert E. Michler, MD, Karl P. Klassen Professor of Surgery, Chief, Division of Cardiothoracic Surgery, Doan Hall North, Ohio State University Medical Center, 410 West 10th Ave., Columbus, OH 43210.

Copyright (c) 1998 by Mosby, Inc.

$0022-5223 / 98 \$ 5.00+0 \quad \mathbf{1 2 / 1 / 8 8 0 1 5}$ 


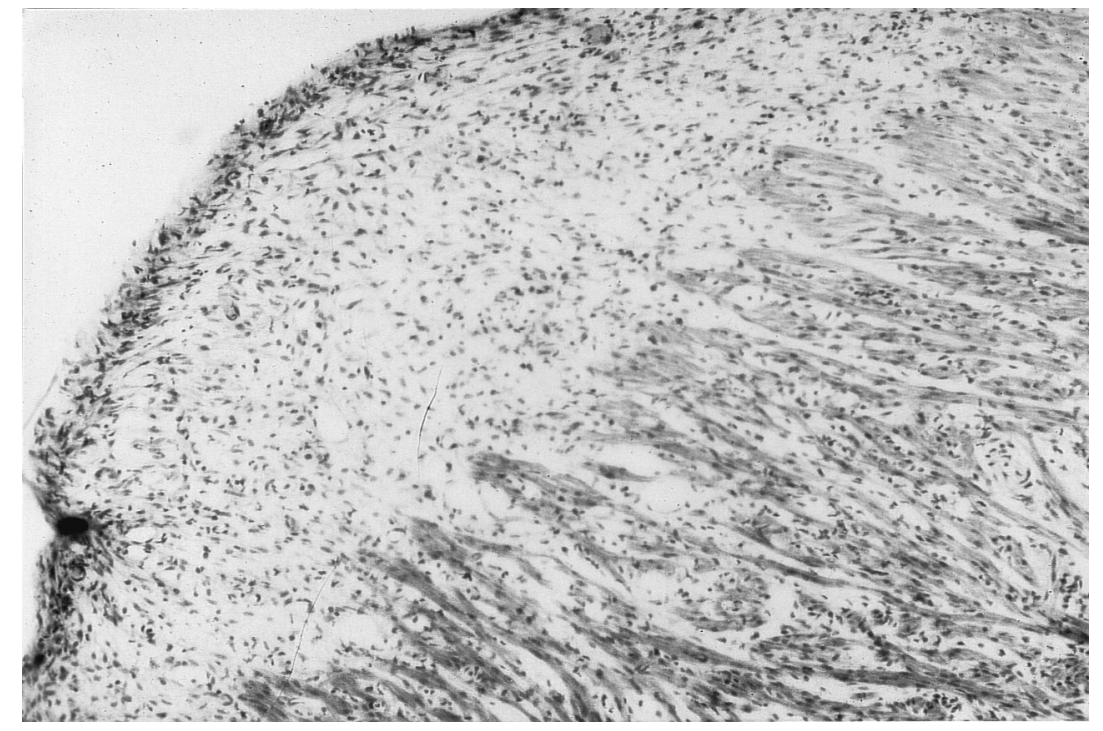

Fig. 1. Micrograph at low power of a heterotopic pig cardiac xenograft placed into an unmedicated newborn baboon. This specimen demonstrates a dense mononuclear cell infiltrate. Tissue was obtained at the time of rejection (4 days). This specimen is representative of all control grafts.

and size of pig and human organs, the ease with which pigs can be bred in large numbers, and their relative lack of pathogens capable of causing infection in human beings make pigs an attractive source of organs.

Mature primates contain high levels of preformed immunoglobulin $\mathrm{M}$ (IgM) xenoantibody, and grafts transplanted into these animals undergo hyperacute rejection within minutes to hours. ${ }^{1}$ These preformed xenoantibodies are primarily directed to the epitope, Gal- $\alpha-1-3-G a l \quad \beta-1-4-G l c N A c-R(\alpha-G a l){ }^{2}$ Expression of the $\alpha$-Gal residue on cells depends on the presence of a functional gene encoding for the $\alpha$-1,3-galactosyltransferase glycosidation enzyme. The phylogenetically related group of primates, which includes human beings, apes, and Old World monkeys (the platyrrhines), contains an inactivated $\alpha$-1,3-galactosyltransferase gene and does not express $\alpha$-Gal on cell surface structures. In contrast, all other mammalian species contain an intact $\alpha-1,3-$ galactosyltransferase gene and express $\alpha$-Gal on endothelium and other cell lines. ${ }^{3}$

It is thought that anti-Gal antibodies initially develop in human beings, apes, and Old World monkeys after exposure to gut bacterial flora, which also express the $\alpha$-Gal epitope. ${ }^{4}$ Because the newborn gut is sterile, there is an immunologic window during which newborn primates do not have IgM anti-Gal antibodies and do have reduced levels of IgG anti-Gal antibodies. Indeed, IgM xenoantibod-
Table I. Graft survival

\begin{tabular}{ccccc}
\hline \multicolumn{2}{c}{ Control } & & \multicolumn{2}{c}{ Medicated } \\
\cline { 1 - 2 } \cline { 4 - 5 } Baboon & Graft life (days) & & Baboon & Graft life (days) \\
\hline 1 & 4 & & 1 & 6 \\
2 & 3 & & 2 & 6 \\
3 & 3 & & 3 & 6 \\
4 & 4 & & 5 & 8 \\
5 & 4 & & 5 & 8 \\
Average age & Mean $3.6 \pm 0.5$ & Average age & Mean $6.2 \pm 1.1$ \\
36 days & & & 38 days & $p=0.01$ \\
$(28-43)$ & & $(34-40)$ & \\
\hline
\end{tabular}

ies are nearly absent in the serum of newborn human beings and primates and progressively increase to reach adult levels by 2 months of age. As for xenoreactive IgG antibody levels, those in newborn infants are approximately $25 \%$ of those in adults, reflecting passive transfer of maternal $\mathrm{IgG}$ across the placenta. ${ }^{5,6}$ Because newborn human beings and baboons have very low levels of anti-Gal IgM antibodies and reduced levels of anti-Gal IgG antibodies, newborns serve as a natural model of antibody depletion and pig hearts transplanted into baboons do not undergo hyperacute rejection. ${ }^{7}$ Rather, we have previously shown that these grafts are rejected at days 3 to 4 . This rejection process is associated with an infiltration of mononuclear cells (predominately natural killer cells and macrophages) and an induced humoral response. ${ }^{8,9}$ The 


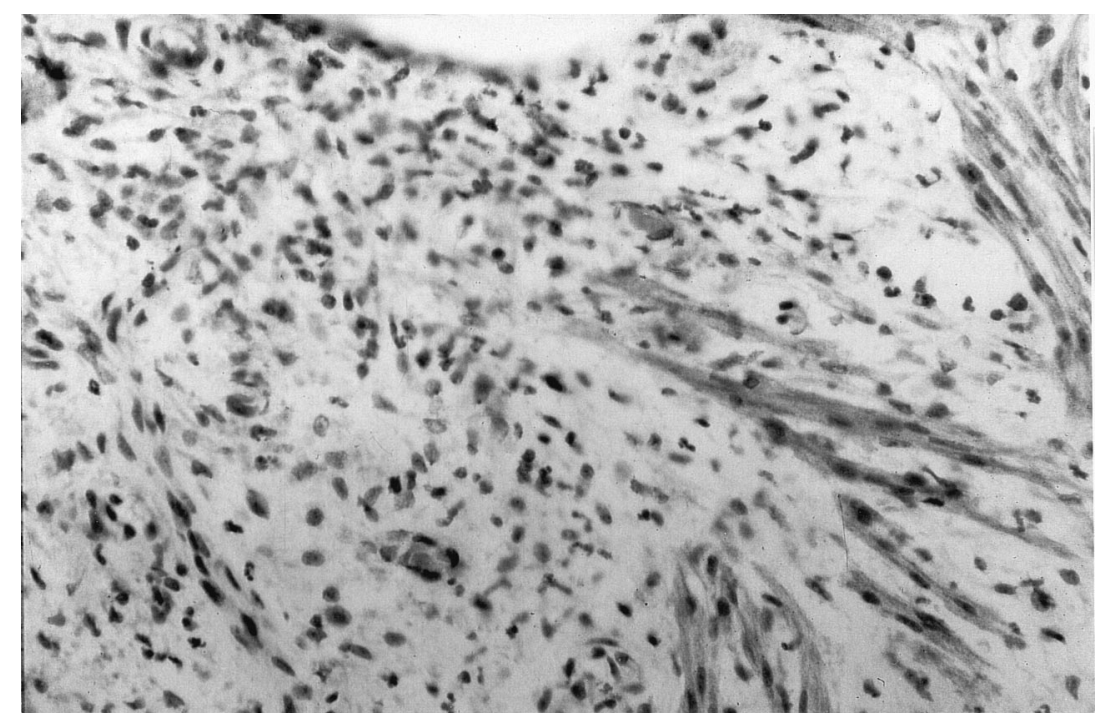

Fig. 2. Micrograph at high power of a heterotopic pig cardiac xenograft placed into an unmedicated newborn baboon. This specimen demonstrates a dense mononuclear cell infiltrate with only a scattering of polymorphonuclear neutrophils. Tissue was obtained at the time of rejection (4 days). This specimen is representative of all control grafts.

importance of natural killer cells and macrophages was first observed in complement-depleted rat recipients of heterotopic guinea pig cardiac xenografts. ${ }^{10}$ This phenomena has been termed "delayed xenograft rejection" and is distinct in its time course and pathogenesis from $\mathrm{T}$ cell-mediated rejection seen in acute allograft rejection.

It has yet to be determined whether "delayed xenograft rejection" in primates can be abated with conventional immunosuppression. Therefore this study sought to investigate the effects of a cyclosporine-based immunosuppressive protocol (INN: ciclosporin), analogous to those used in allotransplantation, on "delayed xenograft rejection" in newborn baboon recipients of pig cardiac xenografts.

\section{Materials and methods}

Animals. Newborn baboons (Papio anubis) were born at the Institute for Comparative Medicine (Columbia University, New York, N.Y.). Expectant mothers were purchased from Biologic Resources Laboratory, Chicago, Illinois. Day-old Yorkshire pigs weighing 1000 gm were purchased from Animal Biotech Industries, Inc., Danboro, Pennsylvania, and used as donors. Approval by the Animal Care and Use Committee of Columbia University was obtained before this study was begun. All animals received humane care in compliance with the "Guide for the Care and Use of Laboratory Animals" prepared by the Institute of Laboratory Animal Resources and published by the National Institutes of Health (NIH Publication No. 86-23, revised 1985). Primates were housed in a facility approved by the American Association for Laboratory Animal Care.

Cardiac transplantation. Heterotopic cardiac xenotransplantations were performed as previously described. ${ }^{11}$ In brief, day-old piglets were sedated with intramuscular ketamine (Aveco, Fort Dodge, Iowa) and intubated. General endotracheal anesthesia was maintained with isoflurane (Anaquest, Madison, Wis.). After isolation of the great vessels, the innominate artery was cannulated with a 20-gauge Angiocath catheter (Deseret Co., Sandy, Utah). After transection of the left inferior pulmonary vein and inferior vena cava, the heart was arrested with cold $\left(4^{\circ} \mathrm{C}\right)$ University of Wisconsin solution (Du Pont Pharmaceuticals, Wilmington, Del.) and chilled with topical cold saline solution. The heart was resected, and the left atrial free wall, as well as the venae cavae, was closed with 7-0 polypropylene suture. The pulmonary artery was transected at its bifurcation and the aorta was transected slightly shorter than the pulmonary artery. The heart was then stored in cold saline solution as final preparation of the recipient was completed.

Newborn baboons weighing 950 to 1300 gm (average age 36 days control, 38 days experimental) were sedated with ketamine, intubated, and maintained under general isoflurane anesthesia. They underwent heterotopic cardiac transplantation, with anastomosis of the graft aorta and pulmonary artery to the common iliac artery and vein, respectively. Rejection of the graft was determined by cessation of graft contraction. At the time of rejection the graft was explanted and the baboon was returned to its mother. The nonparametric Mann-Whitney test was used to determine a two-tailed $p$ value.

Immunosuppression. All recipient baboons received cyclosporine (CsA, Sandimmune, Sandoz Pharmaceuti- 


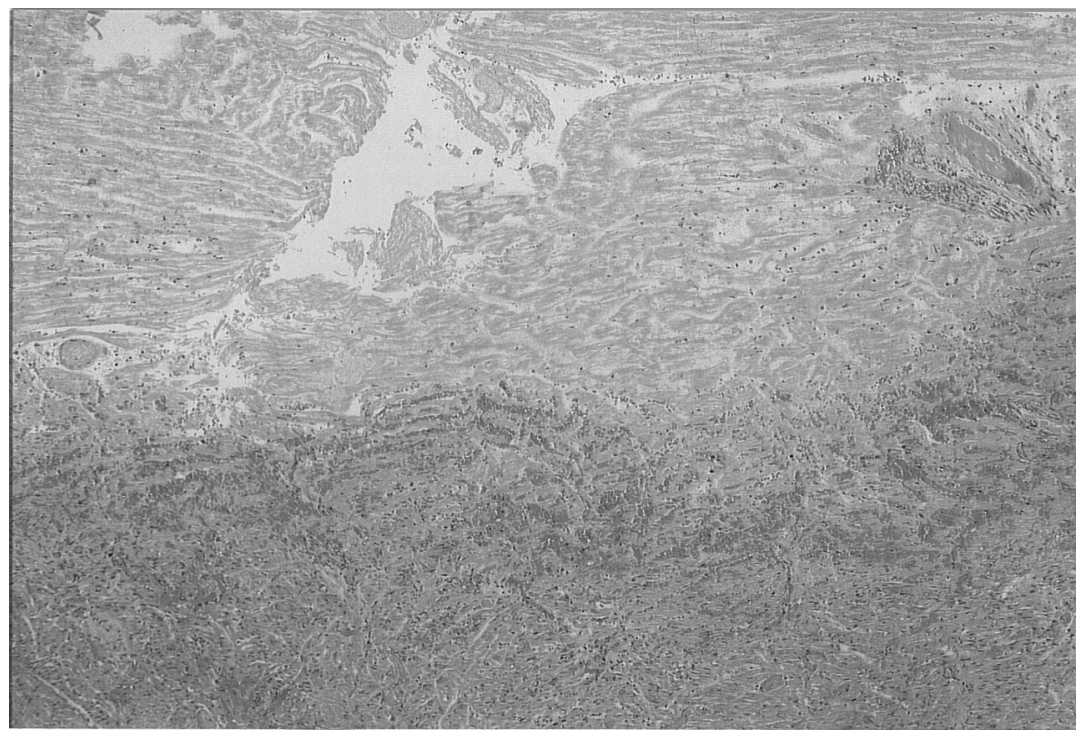

Fig. 3. Low-power micrograph of a heterotopic pig cardiac xenograft placed into a medicated newborn baboon. Tissue was obtained at the time of rejection (6 days). This specimen is representative of all medicated grafts. It demonstrates complement-mediated rejection, with diffuse hemorrhage and edema. There is thrombosis of the artery supplying the myocardium in the upper right corner.

cals, East Hanover, N.J.) $10 \mathrm{mg} / \mathrm{kg}$ daily by intramuscular injection or intravenously from the day of transplantation until rejection. Methylprednisolone sodium succinate (Solu-Medrol, The Upjohn Company, Kalamazoo, Mich.) $15 \mathrm{mg} / \mathrm{kg}$ was given intravenously on the day of transplantation. Daily steroid therapy was then tapered to $1 \mathrm{mg} / \mathrm{kg}$ daily if intravenous access was maintained; otherwise it was switched to $0.8 \mathrm{mg} / \mathrm{kg}$ daily of methylprednisolone acetate by intramuscular injection (Depo-Medrol, Upjohn). In addition to the CsA and steroids, baboons received mycophenolate mofetil (MMF, CellCept, Roche Laboratories, Nutley, N.J.). One week before transplantation, recipients received MMF $100 \mathrm{mg} / \mathrm{kg}$ every other day by subcutaneous injection; once the transplant operation was done, they received daily injections. All immunosuppression was stopped once the graft was rejected and explanted. CsA and steroids were purchased through the pharmacy at Columbia-Presbyterian Medical Center. MMF was a gift of Roche Pharmaceuticals.

Serum samples. Recipient baboon serum was obtained from the baboons 1 week before transplantation (before immunosuppression), at the time of rejection, and after graft explantation and cessation of immunosuppression (postoperative days 14 and 21). As a control for the induced anti-Gal response, additional serum samples were taken from a newborn baboon that underwent the same operation as the transplant recipients, but did not receive a xenograft. Each sample was frozen and stored at $-80^{\circ} \mathrm{C}$. The samples were thawed for the first time at the time of antibody measurement.

Enzyme-linked immunosorbent assay studies with $\boldsymbol{\alpha}$-Gal-bovine serum albumin. Anti-Gal activity in the serum of the transplanted baboons was determined in enzyme-linked immunosorbent assay (ELISA) using syn- thetic $\alpha$-galactosyl epitopes coupled to bovine serum albumin (BSA) (Dextra, Reading, United Kingdom) as the solid-phase antigen. Fifty microliters of $\alpha$-gal-BSA at a concentration of $10 \mathrm{mg} / \mathrm{ml}$ in carbonate buffer $(\mathrm{pH} 9.5)$ was placed in microtiter wells (3129 plates; Falcon, Oxnard, Calif.) and incubated for 2 hours at $37^{\circ} \mathrm{C}$ and overnight at $4^{\circ} \mathrm{C}$. The plates were subsequently blocked with $1 \%$ BSA in carbonate buffer $(\mathrm{pH} 9.5)$ to decrease nonspecific binding of immunoglobulins. Fifty-microliter serum aliquots in twofold serial dilution in phosphatebuffered saline (PBS) solution containing 1\% BSA and starting at a dilution of 1:100 were then placed in the wells. After 90 minutes' incubation at room temperature, the plates were washed five times with PBS solution containing $0.05 \%$ Tween. Horseradish peroxidase-conjugated rabbit anti-human IgG or IgM (Dako, Carpinteria, Calif.) was added at a dilution of 1:1000 to each well in 50 $\mathrm{ml}$ aliquots. The plates were further incubated for 1 hour and washed with PBS-Tween. The color reaction was developed with $o$-phenylenediamine dihydrochloride (Sigma Chemical Co., St. Louis, Mo.), and the absorbance was measured in an ELISA reader at $492 \mathrm{~nm}$.

In our experience, the blocking of the ELISA plates cannot completely prevent nonspecific human immunoglobulin binding. Therefore, to assess the specific binding of anti-Gal, we performed a parallel ELISA assay using the neoglycoprotein $N$-acetyllactosamine (Gal- $\beta$-1-4GlcNAc-R)-BSA as a control solid-phase antigen. Primates and other mammals usually lack antibodies to this epitope, because it is normally expressed in various amounts on mammalian cells. The specific binding of anti-Gal was assessed at each serum dilution by subtracting the optical density measured with $N$-acetyllactosamine-BSA from those with $\alpha$-gal-BSA. ${ }^{12}$ 


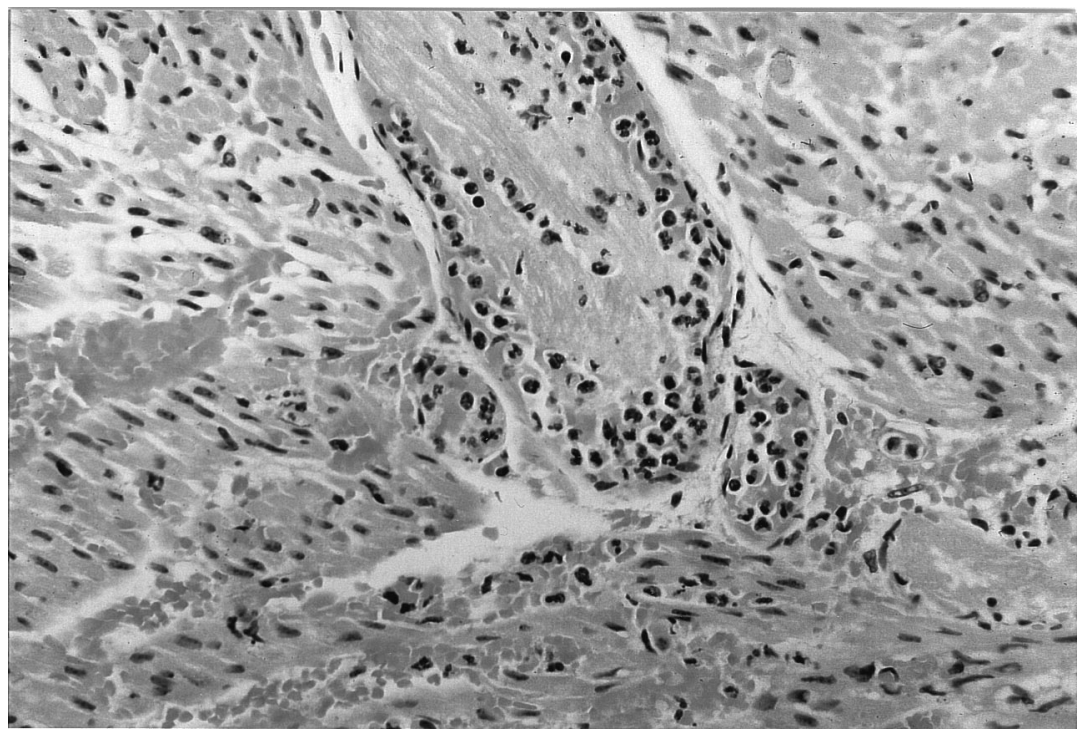

Fig. 4. High-power micrograph of a heterotopic pig cardiac xenograft placed into a medicated newborn baboon. Tissue was obtained at the time of rejection (6 days). This specimen is representative of all medicated grafts. It demonstrates a small artery in cross section, with destruction of the endothelium, thrombosis, and infiltration of neutrophils.

Light microscopy and immunofluorescence. Tissue specimens were placed in formalin, sectioned, and stained with hematoxylin and eosin, or they were placed in embedding medium (OCT compound; Miles, Naperville, Ill.), snap-frozen in liquid nitrogen, and stored at $-80^{\circ} \mathrm{C}$. Frozen tissue sections ( $4 \mathrm{~m}$ thick) were prepared in a Leica cryostat (Leica, Heidelberg, Germany). The sections were air-dried, fixed with acetone, and washed with PBS solution. Deposition of $\mathrm{IgG}, \mathrm{IgM}, \mathrm{C} 3$, and fibrin was detected by incubating each section with fluorescein isothiocyanate-conjugated goat antihuman antibodies (Dako). After incubation, tissue sections were washed with PBS solution and mounted with $p$-phenyenediamine/ glycerol solution. Sections were evaluated with a Leitz DMRB epifluorescence microscope (Leica) and photographed.

\section{Results}

Survival. Triple immunosuppression increased average graft life from $3.6 \pm 0.5$ days $(n=5)$ to $6.2 \pm 1.1$ days $(n=5, p=0.01$, Table I). All of the baboons tolerated the immunosuppression without complication. After graft explantation the baboons were returned to their mothers. The baboons have not had any long-term ill effects from the medication. They have developed normally, with the first baboon recipient now more than 1 year beyond transplantation.

Histology. As shown in Figs. 1 and 2, grafts explanted from untreated recipient animals demon- strated extensive mononuclear cell infiltration. The mononuclear cell infiltration was significantly less in the grafts from the immunosuppressed baboons, but these grafts had extensive areas of hemorrhage, thrombosis, platelet aggregation, neutrophil infiltration, and edema. The graft in Fig. 3 functioned for 6 days and, at explantation, had areas of infarcted myocardium. Fig. 4 shows a small artery in cross section, with denudation of the endothelium, adherence of neutrophils to the endothelial surface, and marked damage to the endothelial cell surface. Furthermore, fibrin is attached to the denuded vascular wall, suggestive of intravascular coagulation.

Immunofluorescence. In untreated animals, immunofluorescence demonstrated the early stages of a humoral response to the graft, with mild focal deposition of $\operatorname{IgM}, \operatorname{IgG}, \mathrm{C} 3$, and fibrin. In contrast, all of the grafts explanted from the medicated baboons showed diffuse and dense deposition of IgM, C3, and complement, with mild deposition of IgG (Figs. 5 to 8). These features are consistent with antibody binding and complement activation despite triple immunosuppressive therapy.

IgM anti-Gal levels. Preoperative newborn baboon sera contained barely detectable levels of anti-Gal IgM. All baboon recipients of a pig xenograft produced anti-Gal IgM after transplantation. 


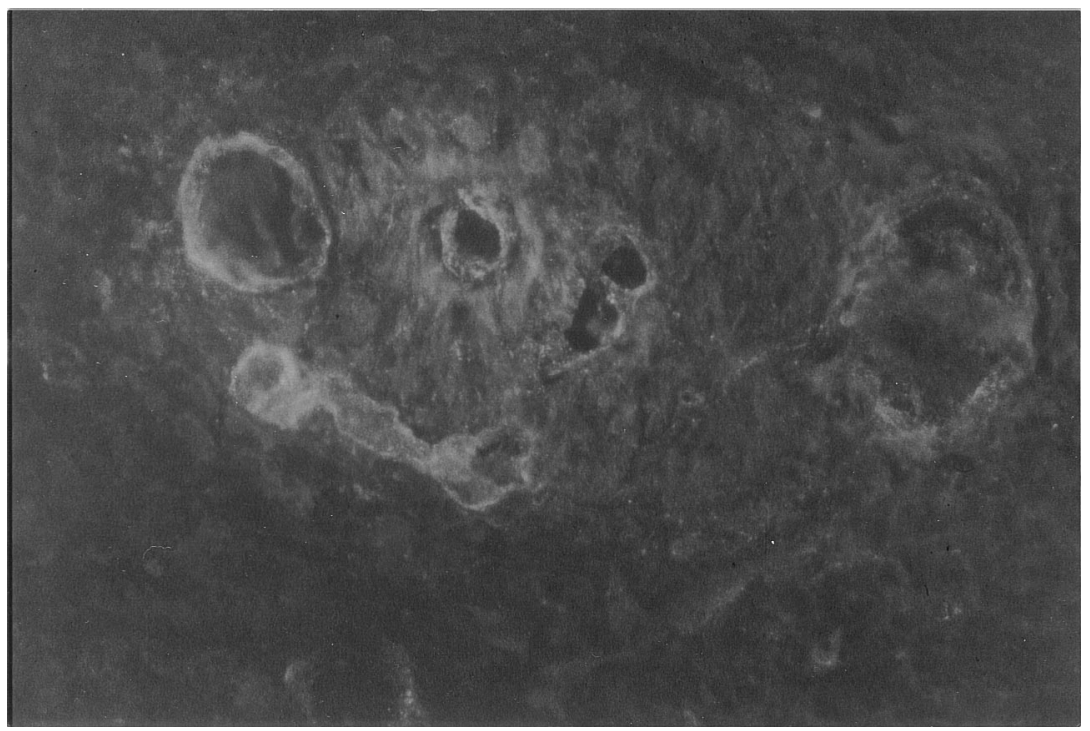

Fig. 5. Immunopathology of a heterotopic pig cardiac xenograft placed into a immunosuppressed newborn baboon. Tissue samples were obtained at the time of rejection (6 days). These samples are representative of all specimens obtained from the immunosuppressed baboons. There is significant deposition of IgM.

Table II describes the changes in anti-Gal IgM concentrations in one of the immunosuppressed baboons. These changes are representative of those seen in all of the baboon pig xenograft recipients. The titer of anti-Gal was defined as the reciprocal of serum dilution, which yields 1.5 O.D. (i.e., $50 \%$ of maximum binding). Interestingly, the anti-Gal IgM titer remained low in the baboon that did not receive a pig xenograft.

The induced IgM anti-Gal response was associated with $\operatorname{IgM}$ deposition in the explanted graft. Two weeks after graft explantation the serum titer remained elevated, but by 3 months the IgM level returned to a level consistent with antibody isotype switching.

IgG anti-Gal levels. Before transplantation all of the baboons had circulating anti-Gal IgG antibody titers ranging from 20 to 320 . The titer of anti-Gal antibody was defined as the reciprocal of serum dilution which yields 1.5 O.D. (i.e., $50 \%$ of maximum binding). At the time of graft explantation, serum anti-Gal IgG antibodies were barely detectable. However, because IgG was detected by immunofluorescence in the explanted graft, this finding suggested that the majority of circulating IgG antibody had bound to the xenograft. After the removal of the graft, the anti-Gal IgG antibody titers rose in all of the baboons that received transplants. In every instance the anti-Gal IgG titer remained elevated or continued to rise at 3 weeks. Table III describes the changes in anti-Gal IgG antibody concentration in one of the immunosuppressed baboons. These changes are representative of all baboon recipients of a pig xenograft. In the one newborn baboon that did not receive a xenograft, there was a gradual decline in anti-Gal IgG antibody titer, consistent with the expected decrease in passively acquired maternal antibody.

\section{Discussion}

The results of this study indicate that CsA-based triple immunosuppression at a dose tolerable by a newborn baboon can increase graft survival. Despite barely detectable levels of IgM anti-Gal xenoreactive antibody at the time of engraftment, this immunosuppressive regimen was not sufficient to prevent an induced $\operatorname{IgM}$ xenoreactive antibody response that led to graft loss on days 6 to 7. Interestingly, it appears that the treated animals demonstrated a less significant macrophage and natural killer cell infiltrate than the untreated animals.

Probably because of the greater duration of xenograft exposure, the serum antibody response was more pronounced in treated recipients than in unmedicated animals. This resulted in a delayed form of humoral rejection with destruction of the entire 


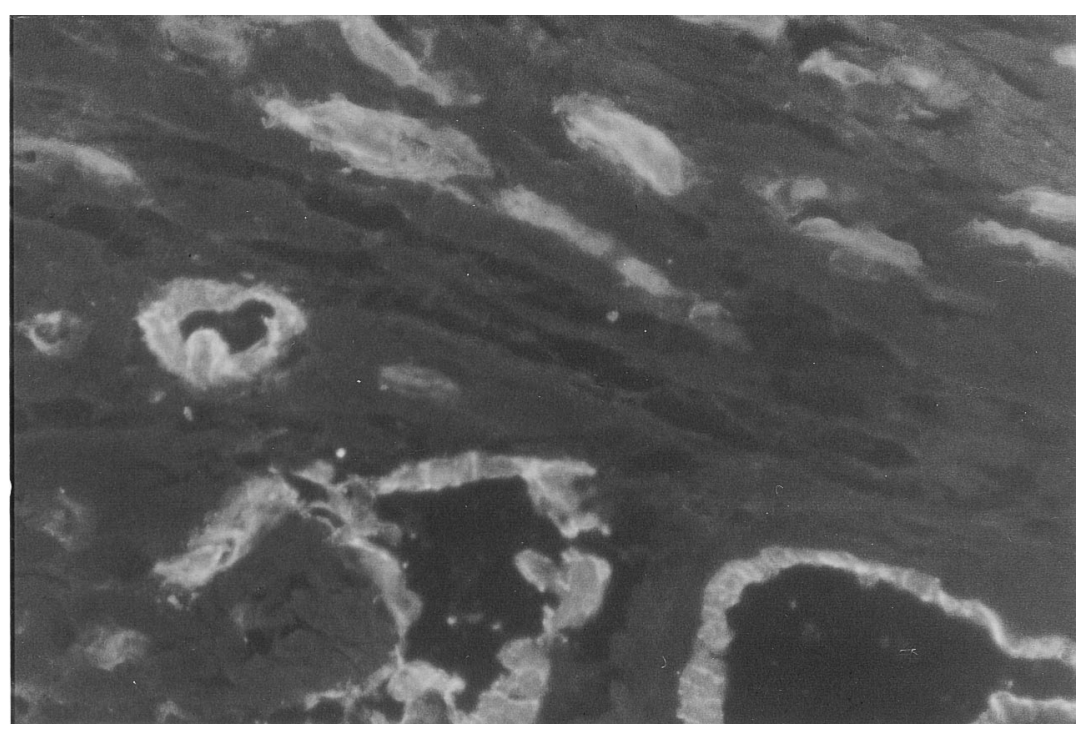

Fig. 6. Immunopathology of a heterotopic pig cardiac xenograft placed into a immunosuppressed newborn baboon. Tissue samples were obtained at the time of rejection ( 6 days). These samples are representative of all specimens obtained from the immunosuppressed baboons. There is significant deposition of $\mathrm{C} 3$.

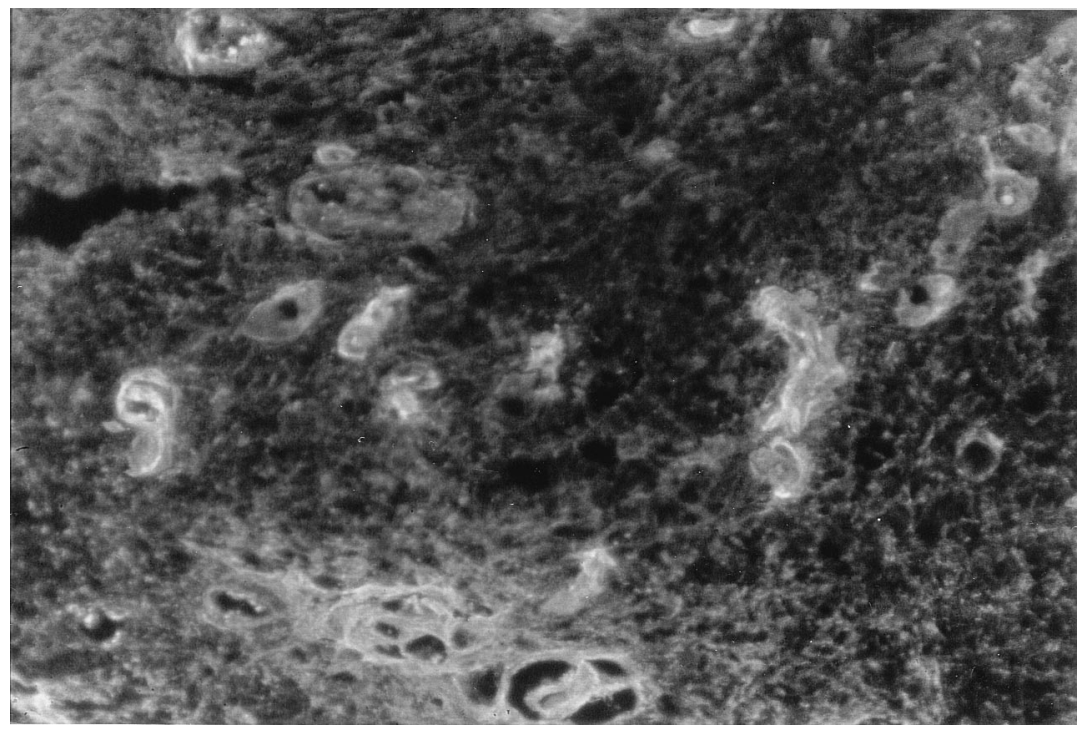

Fig. 7. Immunopathology of a heterotopic pig cardiac xenograft placed into a immunosuppressed newborn baboon. Tissue samples were obtained at the time of rejection ( 6 days). These samples are representative of all specimens obtained from the immunosuppressed baboons. There is significant deposition of fibrin.

vascular bed resulting in ischemic infarction of the myocardium. The time course of the induced humoral response parallels that of a primary IgM response to a new antigen.

In previous studies aimed at elucidating the mechanisms of human natural killer cell lysis of porcine endothelium, we have observed two distinct activation pathways-one involving binding of xenoreactive IgG to CD16 and another resulting from activation with interleukin-2 (lymphokine-activated natural killer cell activity). Interleukin-2 augmented lytic activity is approximately twofold greater than 


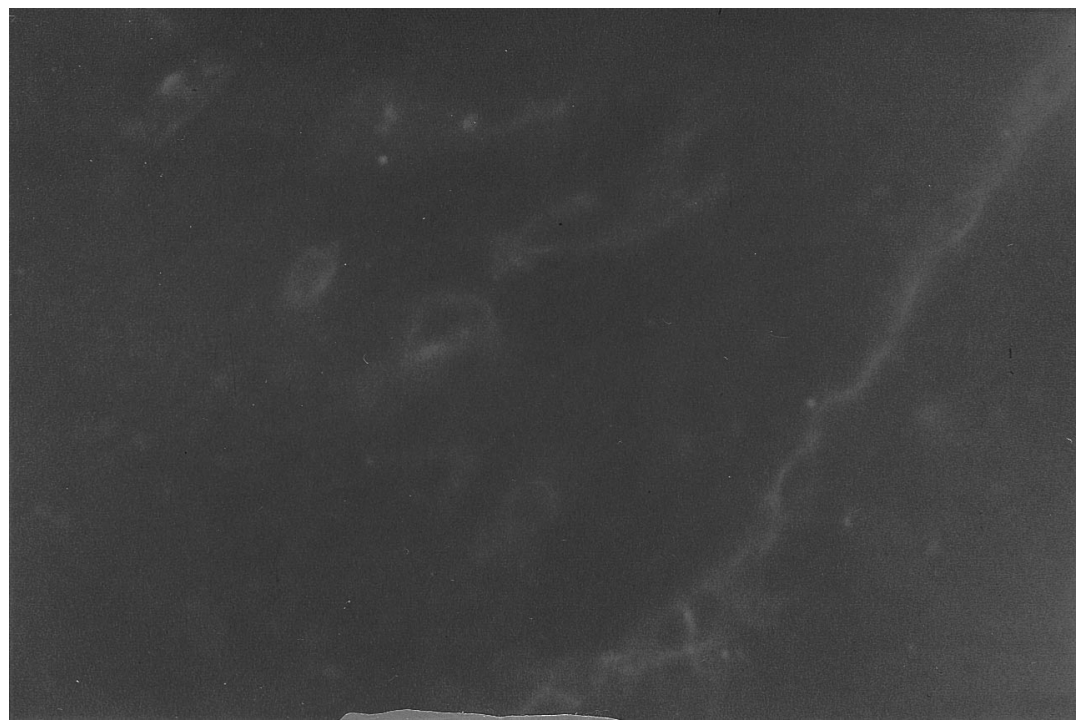

Fig. 8. Immunopathology of a heterotopic pig cardiac xenograft placed into a immunosuppressed newborn baboon. Tissue samples were obtained at the time of rejection (6 days). These samples are representative of all specimens obtained from the immunosuppressed baboons. There is trace deposition of $\mathrm{IgG}$.

Table II. IgM anti-Gal ELISA

\begin{tabular}{lc}
\hline \multicolumn{1}{c}{ Time } & IgM titer \\
\hline Preop. & Absent \\
Rejection & Absent \\
Two weeks & 80 \\
Three weeks & 80 \\
Three months & 40
\end{tabular}

Titer is defined as the reciprocal of the dilution that yields $50 \%$ maximum binding.

antibody-dependent cellular cytotoxicity and is, therefore, likely to be of greater clinical significance. We therefore suspect that the CsA-based immunosuppressive protocol used in this study may have reduced interleukin-2 production and consequently diminished natural killer cell lysis.

An induced donor-specific antibody response can develop in some recipients of allografts. Why these allografts usually are not rejected with the same vigor as a xenograft may be attributed to several factors. Xenoreactive anti-pig antibody is directed at the $\alpha$-Gal epitope, which is expressed as millions of epitopes per cell in porcine cells of ectodermal and mesenchymal origin, whereas allospecific antibody is primarily directed against major histocompatibility antigens, the distribution of which is less dense. On the other hand, ABO-incompatible allografts are at risk for complement-mediated injury. ${ }^{13}$ Like pig
Table III. IgG anti-Gal ELISA

\begin{tabular}{lc}
\hline \multicolumn{1}{c}{ Time } & IgG titer \\
\hline Preop. & 20 \\
Rejection & Absent \\
Two weeks & 640 \\
Three weeks & 1280 \\
Three months & 1280 \\
\hline
\end{tabular}

Titer is defined as the reciprocal of the dilution that yields $50 \%$ maximum binding.

xenografts, ABO-incompatible allografts express a carbohydrate epitope, not in as great a distribution as $\alpha$-Gal, but greater than the major histocompatibility antigens. The greater distribution of antigen, therefore, results in greater IgM binding and more efficient complement activation. Additionally, membrane-bound complement regulatory proteins (homologous restriction factor, decay-accelerating factor, and membrane cofactor protein) are species-specific and therefore probably less effective in protecting a xenograft from complement-mediated injury.

The immunosuppressive regimen used in this study is comparable with that used in clinical allotransplantation. We have previously demonstrated that CsA given to baboons by intramuscular injection at a dose of $10 \mathrm{mg} / \mathrm{kg}$ daily will result in serum trough concentration of 300 to $500 \mathrm{ng} / \mathrm{ml}^{14}$ The intraoperative steroid dose of $15 \mathrm{mg} / \mathrm{kg}$ is greater 
than that usually administered in clinical allotransplantation, but it is equivalent to the dose used when ABO-incompatible kidneys have been engrafted, the clinical situation most analogous to this experiment. ${ }^{15}$

In an attempt to inhibit the induced anti-Gal xenoantibody response, we included an anti-B cell agent in the protocol. MMF is a potent, selective, noncompetitive, and reversible inhibitor of inosine monophosphate dehydrogenase. MMF can inhibit the de novo pathway of guanosine nucleotide synthesis. Since T- and B-lymphocyte proliferation is critically dependent on the de novo synthesis of purines, MMF has potent cytostatic effects on lymphocytes. MMF can also inhibit proliferative responses of T- and B-lymphocytes to both mitogenic and allogenic stimulation and potentially suppress antibody formation by B-lymphocytes. At doses of $100 \mathrm{mg} / \mathrm{kg}$, MMF has been shown to inhibit lymphocyte proliferation while allowing for the replication of intestinal basal epithelial cells and germinal cells. $^{16}$

MMF was inadequate to prevent the marked induction of xenoreactive antibody in this model. Additional strategies to prevent complement-mediated xenograft injury will be required to achieve clinically relevant graft prolongation. Such strategies are presently being used in our laboratory and include porcine organs transgenic for human complement-regulatory proteins. It is expected that these organs may one day be used as "a bridge" to allotransplantation, sustaining newborn human beings in need of a heart transplant until an appropriate donor can be found.

\section{REFERENCES}

1. Sandrin MS, Vaughan HA, Dabkowski PL, McKenzie IFC. Anti-pig IgM antibodies in human serum react predominantly with Gal- $\alpha-1,3-G a l$ epitopes. Proc Natl Acad Sci U S A 1993;90:11391-5.

2. Parker WR, Bruno D, Holzknecht ZE, Platt JL. Xenoreactive natural antibodies: isolation and initial characterization. J Immunol 1994;153:3791-803.
3. Galili U, Shohet SB, Kobrin E, Stults CM, Macher BA. Man, apes, and old-world monkeys differ from other mammals in the expression of $\alpha$-galactosyl epitopes on nucleated cells. J Biol Chem 1988;263:17755-62.

4. Galili U, Mandrell RE, Hamahdeh RM, Shohet SB, Griffis JM. Interaction between human natural anti- $\alpha$-galactosyl immunoglobulin $\mathrm{G}$ and bacteria of the human flora. Infect Immunol 1988;56:1730-34.

5. $\mathrm{Xu} \mathrm{H}$, Edwards NM, Chen JM, Dong X, Michler RE. Age-related development of human anti-pig xenoantibody. J Thorac Cardiovasc Surg 1995;110:1023-9.

6. Galili U, Rachmilewitz EA, Peleg A, Flechner I. A unique natural human IgG antibody with anti- $\alpha$-galactosyl specificity. J Exp Med 1984;160:1519-23.

7. Michler RE, Xu H, O'Hair DP, Shah A, Kwiatkowski PA, Minanov OP, et al. Newborn discordant cardiac xenotransplantation in primates: a model of natural antibody depletion. Transplant Proc 1996;28:661-2.

8. Itescu S, Kwiatkowski P, Wang SF, Blood T, Minanov OP, Rose S, et al. Circulating human mononuclear cells exhibit augmented lysis of pig endothelium after activation with interleukin 2. Transplantation 1996;62:1927-33.

9. Minanov OP, Itescu S, Neethling FA, Morenthau A, Kwiatkowski P, Cooper DKC, et al. Anti-Gal IgG antibodies in sera of newborn humans and baboons and its significance in pig xenotransplantation. Transplantation 1997;63:182-6.

10. Blakely ML, Van der Werf M, Brendt MC, Dalmasso AP, Bach FH, Hancock WW. Activation of intragraft endothelial and mononuclear cells during discordant xenograft rejection. Transplantation 1994;58:1059-64.

11. Minanov OP, Kwiatkowski P, Popilskis S, Michler RE. A modified technique for heterotopic heart transplantation in small primates. Ann Thorac Surg 1997;63:258-60.

12. Galili U, LaTemple DC, Walgenbach AW, Stone KR. Porcine and bovine cartilage transplants in cynomolgus monkey: changes in anti-galactose response during chronic rejection. Transplantation 1997;63:646-51.

13. Galili U, Tibell A, Samuelsson B, Rydberg L, Groth CG. Increased anti-Gal activity in diabetic patients transplanted with fetal porcine islet cell clusters. Transplantation 1995;59: 1549-56.

14. Michler RE, McManus RP, Smith CR, Sadeghi AN, Marboe $\mathrm{CC}$, Reemtsma K, et al. Prolongation of primate cardiac xenograft survival with cyclosporine. Transplantation 1987; 44:632-6.

15. Chopek MW, Simmons RL, Platt JL. ABO-incompatible kidney transplantation: initial immunopathologic evaluation. Transplant Proc 1987;19:4553-7.

16. Eugui EM, Mirkowich A, Allison AC. Lymphocyte-selective antiproliferative and immunosuppressive effects of mycophenolic acid in mice. Scand J Immunol 1991;33:175-83. 